\title{
Influences of Social Capital on Natural Disaster Research in Japan
}

\author{
Ayano Yamaguchi ${ }^{1}$, Min-Sun $\mathrm{Kim}^{2}$, Atsushi Oshio ${ }^{3} \&$ Satoshi Akutsu ${ }^{4}$ \\ ${ }^{1}$ College of Community and Human Services, Rikkyo University, Saitama, Japan \\ ${ }^{2}$ Communicology, University of Hawaii at Manoa, Hawaii, USA \\ ${ }^{3}$ Faculty of Letters, Arts and Sciences, Waseda University, Tokyo, Japan \\ ${ }^{4}$ Graduate School of International Corporate Strategy (ICS), Hitotsubashi University, Tokyo, Japan \\ Correspondence: Ayano Yamaguchi, Rikkyo University, College of Community and Human Services, 1-2-26 \\ Kitano, Niiza-shi, Saitama Japan 352-8558. Tel: 48-471-7429. E-mail: ayanoy@rikkyo.ac.jp
}

Received: January 18, 2017

Accepted: May 2, 2017 Online Published: May 31, 2017

doi:10.5539/jsd.v10n3p46

URL: https://doi.org/10.5539/jsd.v10n3p46

\begin{abstract}
The purpose of this study is to seek fresh insight into those aspects of social capital that increase individuals' health and well-being after a disaster such as the Great East Japan Earthquake of 2011. This paper is organized as follows. The theoretical development of the social capital is presented in a literature review. Then, the design and results of the free answers in the open-ended question is described. Finally, this study investigates whether previous findings on the bright and dark sides of social capital and psychological stress are confirmed and highlights how the bright and dark sides of social capital has affected psychological stress, health, and well-being in Japanese disaster context. In other words, the significant mechanisms and roles of social capital in a disaster context is explored. Based on the findings, the theoretical and practical contributions of this study to disaster research are discussed.
\end{abstract}

Keywords: social capital, disaster context, great east Japan earthquake, psychological stress, health and well-being

\section{Introduction}

Previous studies in the health literature tend to discuss the positive association between social capital and well-being (Morgan, Rivera, Moreno, \& Haglund, 2012; Summarch, 2011). However, only a few studies have focused on the relationships between significant forms of social capital, psychological stress, and their effects on health and well-being in disaster context, such as the Great East Japan Earthquake of 2011. Further, while the presence and accessibility of critical infrastructure and resources have been recognized as important in disaster management, the field research lacks a theoretical framework focusing on the role of social capital and psychological stress in enhancing community empowerment (Aldrich, \& Meyer, 2015).

Although emotional and social development of communities are seen within the disaster management field as important aspects of social relationships and socialization, theoretical explanations of social capital in the disaster research have received far less attention. Little research of the micro, mezzo, and macro level perspectives. Instead, most disaster research has focused more on the community. No consensus exists in the health research literature regarding the effect of social capital and psychological stress on well-being, nor is there agreement regarding how to define and measure social capital, making it a challenging issue in disaster research and one requiring further investigation (Ono 2012; Kawachi, 2013).

The purpose of this study was to provide richer detail about the impact of social capital and psychological stress on individual health and well-being in a disaster context such as the Great East Japan Earthquake of 2011. The literature review presents the theoretical development of social capital and psychological stress in the disaster context and is followed by descriptions of the study design and results. The discussion section details whether previous qualitative findings regarding such relationships were confirmed or challenged and highlights how social capital affects health and well-being in a disaster context in Japan. The theoretical and practical contributions of this study to the field of disaster research also are described.

\subsection{The Great East Japan Earthquake of March 11, 2011}

The Great East Japan Earthquake occurred on March 11, 2011, causing a tsunami and a catastrophic nuclear 
accident in Fukushima. The earthquake, which was centered off the coast of Japan, had an estimated magnitude of 9.0 on the Richter scale (Daily Yomiuri, 2011). Due to the resulting nuclear accident in Fukushima, the earthquake has garnered a great deal of international attention. For example, The Telegraph reported that the Fukushima Daiichi nuclear power plant remains far from recovered as the damaged regions. It is from 150 miles northeast of Tokyo, Japan, was severely damaged by the Great East Japan Earthquake and tunami with its crucial cooling systems knocked out, which comes to be meltdowns as the worst nuclear accident in the world (The Telegraph, 2011).

Various researchers explored the psychological stress of the Great East Japan Earthquake on the Japanese people (Ishino, Ogaki, Kamesaka, \& Murai, 2011; Uchida, Takahashi, \& Kawahara, 2014). However, they have not focused on the role of social capital on trust, help, and support, which may be linked to well-being both before and after the disaster.

\subsection{Social Capital}

With its long history of use as an umbrella concept in the social sciences, social capital can be defined as the institutions and norms in social relationships that shape the quality and quantity of social interactions. Overall, social capital from the individual or collective perspective contains the components in common. However, the measurement of these components varies. Regardless of how one conceptualizes social capital, social trust is a key element (Putnam, 2002). Kawachi and Berkman (2000) define social capital as "those features of social structures-such as levels of interpersonal trust and norms of reciprocity and mutual aid-which act as resources for individuals and facilitate collective action. Social capital thus forms a subset of the notion of social cohesion" (p. 175). Similarly, Fujiwara, Yamaoka, and Kawachi (2016) proposed that social capital occurs when an individual gains the trust of a community and access to the community's social resources via his or her social networks and supports.

Thus, social capital is an asset and a social resource both for individuals - who may derive it from their ties to other individuals, groups, or institutions - and for collectives - who may obtain social capital from linkages among various networks, organizations, institutions, and communities. In the context of disasters and their aftermath, social capital is viewed as the "core engine of recovery" (Aldrich, 2012, p.15). People with social capital in a disaster context can access needed information and support and, therefore, recover better than those without social capital. Lack of community social capital may lead to disadvantages, such as the adoption of negative or weak approaches to recovery (Aldrich, 2012). All of the definitions of social capital discussed above are used (Aldrich, 2012; Fujiwara, Yamaoka, \& Kawachi, 2016; Kawachi \& Berkman, 2000).

\subsection{Social Capital in a Disaster Context}

Social capital is considered a "collective asset" and a "common good" of neighborhoods and communities (Putnam, 2000). Putnam (2000) suggests that there are three types of social capital: bonding, bridging, and linking. Bonding is defined as the interpersonal relationships among relatively homogeneous groups (e.g., ethnic, religious, or socioeconomic) that strengthen their internal social ties. Bridging is defined as the social integration of institutional relationships among heterogeneous groups. Linking is defined as the norms, solidarity, and reciprocity of community resources among individuals and groups from different social strata in a hierarchy in which power, social status, and wealth are accessed by the different groups. This study employs all three of these types of social capital.

The most common form of social capital available after disasters is bonding social capital (Norris, Friedman, Watson, Byrne, Diaz, \& Kaniasty, 2002). For example, in the case of an earthquake, bonding social capital roles include individuals who identify warning signs; undertake disaster preparation; identify the locations of shelter, social recourses, and supplies; and receive immediate and recovery assistance (Hawkins \& Maurer, 2010; Heller, Alexander, Gatz, Knight, \& Rose, 2005). The existence of bonding social capital may play a significant role in decreasing the number of individuals who require assistance from local organizations after a disaster (Beggs, Haines, \& Hurlbert, 1996).

Bonding social capital have played an important role in building trust and more widely shared norms among residents after the Kobe earthquakes (Nakagawa \& Shaw, 2004). Even though each different communities within Kobe had different cultural and economic characteristics, those communities with higher social capital and community leadership had greater satisfaction and well-being and were able rebuild and recover quicker (Nakagawa \& Shaw, 2004).

Social capital thus is seen as having a significant effect on resilience in disaster settings. However, bonding social capital can also expose the negative aspects of disasters such as earthquakes. Social capital can be used to 
resist various disaster recovery efforts that are necessary for the public good. For example, in the case of Hurricane Katrina in the United States, before the storm the placement of temporary trailers might have been successfully resisted by those communities with a higher voter turnout (Aldrich \& Crook, 2008). Decision makers and policymakers need to clarify and recognize the potential negative effects of social capital arising from strong in-group cohesion both during and after disasters.

Pfefferbaum, Van Horn, \& Pfefferbaum (2015) explain that in the disaster context,

[b]onding social capital may play a significant role of the assistance and trust which neighbors offer each other aftermath of the disaster. In other words, what communicating the neighbors is to produce their trust each other at the interpersonal level. Bridging social capital may play a key role of social resources and trust which the support survivors obtain from local social services, such as health, religious, business, and other social groups or networks in their community. In other words, what communicating the local social services is to produce their trust each other at the institutional level. Linking social capital may play an important role of disaster management from the disaster-affected groups with social resources available from the government and from various disaster-related organizations and networks. In other words, what communicating the disaster management from the government is to produce their trust each other at the government level. The linking social capital produces in part from improved knowledge about, and access to, various state and federal help social programs to help the survivors in the disaster context (e.g., recovering emotionally, rebuilding their homes, obtaining business loans) (Pfefferbaum, Van Horn, \& Pfefferbaum, 2015).

In the case of the Great East Japan Earthquake, Kurokawa points out the association between the natural disaster and nuclear power in Fukushima. In Japan, the role of social capital and psychological stress may be applicable to this association. In the Japanese collectivist society, the role of social capital may have a negative side (Nuclear Accident Independent Investigation Commission: NAIIC, 2012). Therefore, Kurokawa suggested not only the negative role but also the positive role of social capital in such a disaster context.

Like Pfefferbaum, Van Horn, and Pfefferbaum (2015), Kurokawa points out that a community needs to function well in teams, in that people need to communicate, help, and share with each other. When a disaster management strategy is applied to their community, their volunteer teams can play an important role in it. Such teams are able to work with others in the community, focusing social cohesion and social capital that can improve the functioning of community members and teams. Team leadership and teamwork are able to increase these teams' knowledge about, access to, and use of the disaster care system linking to their communities to external and internal sources of support and mutual aid (NAIIC, 2012; Institute of Medicine (IOM), 2015; Pfefferbaum, Van Horn, \& Pfefferbaum, 2015). Thus understanding the negative role of social capital and psychological stress can be helpful for developing the usefulness of its positive side in the disaster context.

To explore these issues, our study addresses the following research questions:

1) To what extent did communities experience both positive and negative changes in social capital in the aftermath of the 2011 disaster in Japan?

2) How is social capital related to the impact of disasters in Japan (e.g., psychosocial stress)?

\section{Method}

This study explored the individuals' daily life experiences from the perspectives of social capital and psychological stress that might be related to health and well-being in the disaster context. The qualitative interviews attempted to provide richer details about the significant role of social capital on health and well-being in the disaster context in Japan.

\subsection{Participants and Procedure}

The 12 municipalities of the Fukushima Region in Japan were selected because of their representativeness of the geographic and demographic diversity of Fukushima. In this study, the 12 municipalities of Fukushima Region in Japan are Futaba, Okuma, Tomioka, Naraha, Namie, Hirono, Tamura, Minamisoma, Kawauchi, Katsurao, Kawamata, and Iitate.

In the process, the 12 municipalities took part in the questionnaire survey. The questionnaire survey in Japanese included the open ended question as the comments in the free comment space, which were mainly used in this study. Nuclear Accident Independent Investigation Commission, NAIIC initiated the questionnaire survey and comments (2012). The mail survey method were mainly used. The duration of mail survey with the free comment space is from March 15 to April 11, 2012. After the mail surveys were collected, the summaries were made from the free space comments. The summaries which we mainly used in this study were translated into 


\section{English from Japanese.}

The open ended question as the free comment space in the survey research was created, and included a checklist that focused on two main topics: (1) social capital (2) psychological stress. 8,073 (76\%) provided comments in the free comment space from 8,073 (76\%) people in Fukushima Region, Japan provided comments with the consent of the participants and were subsequently transcribed.

The qualitative study was mainly used to find the components of psychological stress, trust in social capital, and socio-demographic characteristics on health and well-being and strengthening social capital on health and well-being in the disaster context such Great East Japan Earthquake of 2011 in Japan.

\section{Results}

The primary goal was to examine the psychological effect of such a huge disaster on the psychological stress, trust in social capital, and sociodemographic characteristics and well-being in Japan by applying a social capital framework. The secondary goal was to analyze and synthesize the major components of psychological stress, distrust and dissatisfaction in the dark side of social capital, and sociodemographic characteristics on disaster contexts in Japan. The third goal was to inform disaster research and improve our conceptual framework for relationships between social capital and disasters in Japan.

Table 1. Qualitative open-ended question texts

\begin{tabular}{lr}
\hline Social Capital in the Disaster Context in Japan & $\%$ \\
\hline Causes of the accident should be probed ASAP, and outcome of the study fully disclosed. & 14 \\
Demand for a thorough investigation in order to never let a similar accident happen again. & 11 \\
Information issued by and behavior of government are unreliable and not trustworthy. & 8 \\
Information issued by and behavior of TEPCO are unreliable and not trustworthy. & $\%$ \\
\hline Psychological Stress in the Disaster Context in Japan & \\
\hline
\end{tabular}

I can't help but feel anxious about children and the future. I have no idea how one is supposed to live like this.

Constantly under stress due to unfamiliar environment, prolonged refugee life, feeling anxious about future, etc.

Suffering poor health because of stress.

Families are separated. We don't see each other much and miss each other. 4

Wish for quick recovery of the lives we had. Wish for "restoring" ordinary life. 3

Feeling of fear that (adult) health might be negatively affected by radiation, and health may deteriorate once medication or outpatient treatment is stopped.

Need for clarification on what we should do. Demand for a release from the current living situation and to settle down.

Fear that health of children and unborn children might be affected by radiation exposure. (Also concerned about the decline in physical strength and the growth of children).

Relatives, friends and neighbors are separated. Losing contact with them and missing each other.

Very sad to see the familiar homeland contaminated by radiation. Feeling of being bogged down day-to-day, no joy, no hope.

So disappointed not to be able to enjoy a comfortable retirement life after the accident. 1

Frustrating to question why one has to lead such a life.

Lost a family member or a friend because of sickness stemming from fatigue following evacuation or because of the stress of evacuation life.

\begin{tabular}{lr}
\hline Others & 38 \\
\hline Total & 100 \\
\hline
\end{tabular}

\subsection{Social Capital in a Disaster Setting}

Table 1 showed the bright side and dark side of social capital in the disaster contexts in Fukushima, Japan. With 
the regard to the perceptions of the bright side of social capital and trust in the disaster contexts of Japan, respondents gave their answers to report any support or help received from friends and family as the interpersonal relationship level, any social groups as the institutional relationship level, and any countries as the society, government, or global level, they were a member of, and any communities in which they were involved. They gave their answers to think widely about the different types of support from the interpersonal, institutional, and society relationship levels that they might have received over the previous year afterword the disaster in Japan, including emotional, economic, and instrumental (help to know or do things). The open ended responses about the perception of trust in the bright side of social capital in the disaster contexts revealed crucial important cultural differences between the participants in Fukushima, Japan. In Fukushima, Japan, the respondents reported few opportunities to build trust, which could be distrust, or to create social ties in order to obtain work or help when it was most needed from the bright side of social capital. Factors such as the recent economic crisis and social problems contributed to the respondents in the disaster contexts, in Fukushima, Japan experiencing uncertainty about their future, feelings of hopelessness, and a lack of successful role models. The respondents reported having negative emotions and feelings of daily life events and high level of perceived psychological stress status. This indicates that the respondents in Japan are most likely to feel stress, distress, and suffer from depression due to a lack of social networks, support, trust, and motivation to obtain the better health status and well-being in the disaster contexts, Fukushima, Japan.

When the respondents in Japan faced challenges in the past, they were more likely to cooperate and resolve them because of the mutual trust in the dark side of social capital and each other. When the economic crisis and financial problems emerged in 2008, they caused a lot of retrenchment, and resulted in a higher level of distrust in the dark side of social capital and each other. (Hibino, Takaki, Ogino, Kambayashi, Hitomi, Shibata, \& Nakamura, 2012; Japan Times, 2009; Tokuda, Fujii, Jimba, \& Inoguchi, 2009).

Previous research has generally focused on the bright side of social capital. This study instead emphasizes the distrust among respondents in Japan to the dark side of social capital. For those who survived the Great East Japan Earthquake of 2011 of Japan 2011 and tsunami, which caused the Fukushima Daiichi Nuclear Plant explosion, their social anxiety was derived from distrust in linking social capital with their government and social uncertainty about scientific information (Tateno \& Yokoyama, 2013). As a result, people in Japan might have strong social connections, but they still distrust the government. This distrust of the government is an aspect of the dark side of social capital. Thus, the current study focuses on the negative aspects of social capital, which leads to distrust and dissatisfaction among even those with strong social connections (Portes \& Landolt, 1996). In examining the opposing possibilities leading to the bright side of social capital, which is commonly discussed in health-science research and disaster research, focusing on a new factor, "tolerance," is important. Tolerance is a notion that the original social capital theory by Putnam (2002) failed to consider. To continue being democratic "joiners" in the public arena, where heterogeneous worldviews, antagonistic partisans, and/or incompatible policy supporters are all present, people must be tolerant of different ideas and ideologies. Tolerance is related to trust, a well-discussed element of social capital; however, it has less to do with trust and is more directly relevant to people's attitudes toward social control (permissiveness) of the deeds of others (Putnam, 2002).

When intolerance prevails, the social system runs the risk of transforming the trust in the bright side of social capital into the distrust in the dark side of the social capital. Under such circumstances, social capital cannot work well and surveillance is needed at all times; antagonism prevails despite the existence of active voluntary associations. The dark side of social capital was first identified and indicated in early arguments Portes and Landolt (1996) and Putnam (2002), who also discussed this perspective directly, mainly in terms of tolerance, although in a quiet, optimistic tone (Hibino et al., 2012; Tokuda et al., 2009).

\subsection{Psychological Stress}

Table 1 shows the psychological stress in the disaster contexts in Fukushima, Japan. The roles of coping strategies, helps, and supports from social resources in their communities may not be always available or sufficient and may not always be relied upon (Japan Times, 2009). The lack of helps and supports resulted in an escalation of their psychological stress and health problems (Hibino, Y., Takaki, J., Ogino, K., Kambayashi, Y., Hitomi, Y., Shibata, A., \& Nakamura, H., 2012; Tokuda, Fujii, Jimba, \& Inoguchi, 2009). Although these respondents considered asking for help and support, they ended up facing their personal and social problems themselves. Even if some Japanese wanted to talk to their friends, they were less likely to get the help and support they needed because they were less likely to rely on friends. For example:

These statements show that Japanese are most likely to feel stress, distress, and suffer from depression due to a lack of social networks, support, trust, and motivation when it comes to investing human capital in a disaster 
context. Although support and trust in a social capital network used to exist, the respondents reported that this was no longer true. These findings suggest that negative perspectives about trust in social capital may be spreading in Japan. The role of social capital can have negative social consequences when it results in rigid in-groups. Otherwise, social capital can become weaker when individuals develop skepticism about the help and support they might receive from others and when they reduce their social involvement with others.

Table 1 shows that health care practitioners and professionals pay attention to influence the role of social capital on psychological stress, health, and well-being in the disaster contexts of Japan. The qualitative finding in this study, there was a lower level of trust in general and a lower sense of community in Japan. Thus, this leads to decreasing levels of social solidarity in the disaster context in Japan. It leads the significant mechanisms and roles of the dark side of social capital and psychological stress in the disaster contexts in Fukushima, Japan.

\section{Discussion and Conclusions}

This qualitative open-ended question investigation has provided a powerful tool for a more in-depth exploration of the associations and relationships among significant social capital and their impacts on health and well-being including psychological stress in the disaster context in Japan. The findings of the in-depth open-ended questions indicate the following. First, significant social capital - mainly perceptions of trust in social capital—has a significant impact.

After the disaster, bonding social capital connected family members, relatives, and friends together. Bonding social capital promoted strong relationships, kinships, and strong ties, and people recognized its importance. This study also examined Japanese cultural trust in bridging social capital and linking social capital and the effects of such on health and well-being. People in Japan were less likely to trust people in their towns, cities, communities (bridging), and governments (linking) (and thus were more likely to distrust people in their communities and governments) and had lower social capital investments (and thus fewer opportunities to receive support and resources, when needed); however, they had strong social connections with their communities and governments. After the Great East Japan Earthquake of 2011 of Japan, the Japanese people initially recognized their social stress and social pressure; they were hopeless, and they suffered from depression because of a lack of social networks, support, trust, and motivation. Later on, they recognized their social networks, ties, and relationships with family members and friends as bonding social capital. This was a good chance for them to recognize and reconsider their bonding social capital so that they can overcome their stress and depression. Losing trust in bridging and linking social capital is likely to produce social pressure, social anxiety, and social stress, ultimately resulting in higher levels of stress and lower levels of health and well-being, including psychological stress in the disaster context (Hibino et al., 2012; Tokuda et al., 2009).

The respondents' self-reported psychological stress was related primarily to the disaster and to the recovery process. This study identified the important indicators of psychological stress and the significant role of bonding social capital and of the loss of bridging and linking social capital following the Great East Japan Earthquake of 2011 of Japan. The findings support our argument that the various changes in the three types of social capital increased psychological stress in a disaster context. This study examined such changes before and after the occurrence of the disaster.

Our findings lead us to conclude that the roles of the three types of social capital are an important consideration of disaster research. As a resource, social capital can diminish the negative impacts of disasters, but at the same time, it can also be negatively affected by a disaster. The negative effects of disaster events on social capital can be cumulative, as demonstrated in this study that focuses on one of the most devastating disasters in Japanese history. Additional research is needed in this area. Specifically, more robust measures of social capital are needed, and an understanding of how social capital theory can be used to facilitate recovery processes, such as rebuilding trust, associations, and norms of reciprocity and creating more disaster-resilient communities, is needed.

In sum, this study has reported the results of open-ended questions designed to achieve a deeper understanding of communities that experienced positive and negative changes in three types of social capital in the aftermath of a disaster in Japan. The relationship between the three types of social capital and the effects of the disaster in Japan (e.g., psychosocial stress) was identified in this study.

Some limitations of this study should be explained. The cross-sectional nature of the data is the most serious: The findings in this study showed only the differences in behavioral structures across groups; the findings may not shed light on social relationships, such as social capital and change within groups over time (Poortinga, 2006; Portes \& Landolt, 1996; Putnam, 2000). The use of self-reporting through the open-ended questions in the questionnaire survey may represent a qualitative limitation as well. 
For the policy implications, the findings in this study may provide practical input for social and health care services or medical services. This study is to identify how significant social capital can have an impact on health and well-being in the disaster setting in Japan - more specifically and precisely, to find the social factors that make individuals more or less resilient. The role of social capital may play in fostering a safe, healthy community and environment. Kurokawa (NAIIC, p. 9) stated "man-made" as follows (Japan Times, 2012; New York Times, 2012).

Kurokawa (NAIIC, p. 9) pointed out the mindset of Japanese people about the Great East Japan Earthquake and Fukushima Daiichi nuclear power disaster and accident. Kurokawa explained the disaster and accident seemed to be caused and damaged by the human from the cultural perspectives in Japan. Apparently, the natural disaster was naturally happened by itself. However, Kurokawa claimed that the collectivistic society like Japan should manage to control the nuclear system and the people. The dark side of social capital may be apparent through the Great East Japan Earthquake and Fukushima Daiichi nuclear power disaster and accident (NAIIC, 2012). Kurokawa also claimed the Japanese society itself should take the responsible for the nuclear power disaster and accident and reflect it for themselves as the democratic and civil society representative in the world. We expect this initiative can continue to develop the legislature and independence of Japanese bureaucracy (NAIIC, 2012).

In order to address our findings, Pilling (2014) stated that: "Kurokawa's sweeping cultural pronouncement invited obvious rejoinders. One was that, by blaming society as a whole, he had cleverly let individuals off the hook. If one minded, one could even draw parallels with the collective assessment of Japan's wartime responsibility" (Pilling, 2014). Murakami and Kurokawa (Japan Times, 2011) pointed out that in Japan, people should independently consider the grassroots and civil society and governments from the various parts in Japan. It is time to open the chance to transform the value and social norms from the collectivistic society in Japan to civil society in Japan, regardless of depending on the government in Japan. Kurokawa also suggested that the government in Japan should invite continuous comments, analyses, and inputs from the Fukushima accident and to keep the input and decision-making processes in order to provide good governance in civil society (National Academy of Science, 2014).

\section{Acknowledgements}

The authors wish to thank Prof. Nancy D Lewis, the director of East West Center, Honolulu, Hawaii, US. They also thank Prof. Kiyoshi Kurokawa, Global Health Innovation Policy Program (GHIPP) and the staff members for their invaluable assistances for this research study. We are grateful for grants received for Academic Research Support Expenses, from Otsuka Pharmaceutical Co., Ltd. These grants include a Grant-in-Aid for Scientific Research B (25285113), Grant-in-Aid for Scientific Research C (25380893), and Grant-in-Aid for Scientific Research C (15K04142).

\section{References}

Aldrich, D. P. (2012). Building Resilience: Social Capital in Post-Disaster Recovery. Chicago: University of Chicago Press. https://doi.org/10.7208/chicago/9780226012896.001.0001

Aldrich, D. P., \& Crook, K. (2008). Strong civil society as a double-edged sword, siting trailers in post-Katrina New Orleans. Political Research Quarterly, 61, 379-389. https://doi.org/10.1177/1065912907312983

Aldrich, D. P., \& Meyer, M. A. (2015). Social Capital and Community Resilience. American Behavioral Scientist, 59(2), 254-269. https://doi.org/10.1177/0002764214550299

Beggs, J. J., Haines, V., \& Hurlbert, J. S. (1996). The effects of personal network and local community contexts on the receipt of formal aid during disaster recovery. International Journal of Mass Emergencies and Disasters, 14, 57-78.

Daily Yomiuri. (2011). 2000 missing in 2 towns: Magnitude of Friday's quake revised upward to 9.0. March 14, 2011. Daily Yomiuri.

Fujiwara, T., Yamaoka, Y., \& Kawachi, I. (2016). Neighborhood social capital and infant physical abuse: a population-based study in Japan. International Journal of Mental Health Systems, 10(13), 1-7. https://doi.org/10.1186/s13033-016-0047-9

Hawkins, R. L., \& Maurer, K. (2010). Bonding, bridging and linking: How social capital operated in New Orleans following Hurricane Katrina. British Journal of Social Work, 40, 1777-1793. https://doi.org/10.1093/bjsw/bcp087

Heller, K., Alexander, D. B., Gatz, M., Knight, B. G., \& Rose, T. (2005). Social and personal factors as predictors of earthquake preparation: The role of support provision, network discussion, negative affect, age, 
and education. Journal of Applied Social Psychology, 35(2), 399-422. https://doi.org/10.1111/j.1559-1816.2005.tb02127.x

Hibino, Y., Takaki, J., Ogino, K., Kambayashi, Y., Hitomi, Y., Shibata, A., \& Nakamura, H. (2012). The relationship between social capital and self-rated health in a Japanese population: a multilevel analysis. Environment Health Preventive Medicine, 17, 44-52. https://doi.org/10.1007/s12199-011-0218-x

Institute of Medicine (IOM), Committee on Post-Disaster Recovery of a Community's Public Health, Medical and Social Services, Board on Health Sciences Policy. (2015). Healthy, resilient, and sustainable communities after disasters: Strategies, opportunities, and planning for recovery. Washington, DC: National Academies Press.

Ishino, T., Ogaki, M., Kamesaka, A., \& Murai, S. (2011). Effect of the great East Japan disaster on happiness. Keio/Kyoto Global COE Discussion Paper Series, DP2011-38.

Japan Times. (2009). Editorial: Depression and Suicide, Thursday, October 8, 2009.

Japan Times. (2011). Fukushima crisis fueling the third opening of Japan, December 1, 2011.

Japan Times. (2012). Nuclear crisis mam-made: Diet panel, July 6, 2012.

Kawachi, I. (2013). Can we reduce disparity of life? Inochi no Kakusa wa Tomerareruka. Tokyo: Shogakkan Press. (in Japanese).

Kawachi, I., \& Berkman, L.F. (2000). Social cohesion, social capital, and health. In Berkman L. F., \& Kawachi, I. (Eds.), Social Epidemiology (pp. 174-190). New York: Oxford University Press.

Morgan, A., Rivera, F., Moreno, C., \& Haglund, B. (2012). Does social capital travel? Influences on the Life satisfaction of young people living in England and Spain. BMC Public Health, 12, 138. https://doi.org/10.1186/1471-2458-12-138

Nakagawa, Y., \& Shaw, R. (2004). Social capital: A missing link to disaster recovery. International Journal of Mass Emergencies and Disasters, 22, 5-34.

National Academics of Sciences. (2014). Lessons learned from the fukushima nuclear accident for improving safety of U.S. Nuclear Plants. The National Academics Press.

New York Times. (2012). Inquiry Concludes That Number Crisis in Japan Was a 'Man-Made Disaster, New York Times.

Norris, F. H., Friedman, M. J., Watson, P. J., Byrne, C. M., Diaz, E., \& Kaniasty, K. (2002). 60,000 disaster victims speak: Part I. An empirical review of the empirical literature, 1981-2001. Psychiatry, 65, 207-239. https://doi.org/10.1521/psyc.65.3.207.20173

Nuclear Accident Independent Investigation Commission, NAIIC. (2012). The Official Report of the Fukushima Nuclear Accident Independent Investigation Commission. Tokyo: National Diet of Japan. Retrieved from http://warp.da.ndl.go.jp/info:ndljp/pid/3856371/naiic.go.jp/en/report/

Ono, H. (2012). The reason that disturbance does not arise after the disaster in Japan: Consideration from the angle of network theory (in Japanese) (Nihon dewa naze shinsaigo ni bodo ga okinai noka: netwaork riron karano ichi-kosatsu). Keizai Seminar, 2-3, 75-79.

Pfefferbaum, B., Van Horn, R. L., \& Pfefferbaum, R. L. (2015). A conceptual framework to enhance community resilience using social capital. Clinical Social Work Journal, published online: 20 August.

Pilling, D. (2014). Bending Adversity: Japan and the Art of Survival. Allen Lane an imprint of Penguin Books.

Poortinga, W. (2006). Social capital: an individual or collective resource for health? Social Science and Medicine, 62(2), 292-302. https://doi.org/10.1016/j.socscimed.2005.06.008

Portes, A., \& Landolt, P. (1996). Downside of social capital. The American Prospect, 7(26), 18-21.

Putnam, R. (2000). Bowling alone: The collapse and revival of American community. New York, NY: Simon \& Schuster. https://doi.org/10.1145/358916.361990

Putnam, R. (2002). Democracies in Flux: The Evolution of Social Capital in Contemporary Society. New York: Oxford University Press. https://doi.org/10.1093/0195150899.001.0001

Summarch, A. H. J. (2011). Facilitating trust engenderment in secondary school nurse interactions with students. Journal of School Nursing, 27(2), 129-138. https://doi.org/10.1177/1059840510392786

Tateno, S., \& Yokoyama, H. M. (2013). Public anxiety, trust, and the role of mediators in communicating risk of 
exposure to low does radiation after the Fukushima Daiichi nuclear plant explosion. Journal of Science Communication, 12, 2.

The Telegraph. (2011). Japan earthquake, tsunami and Fukushima nuclear disaster: 2011, review.

Tokuda, Y., Fujii, S., Jimba, M., \& Inoguchi, T. (2009). The relationship between trust in mass media and the healthcare system and individual health: evidence from the Asia Barometer Survey. BMC Med, 7, 4. https://doi.org/10.1186/1741-7015-7-4

Uchida, Y., Takahashi, Y., \& Kawahara, K. (2014). Changes in hedonic and eudaimonic well-being after a severe nationwide disaster: The case of the Great East Japan Earthquake. Journal of Happiness Studies, 15(1), 207-221. https://doi.org/10.1007/s10902-013-9463-6

\section{Copyrights}

Copyright for this article is retained by the author(s), with first publication rights granted to the journal.

This is an open-access article distributed under the terms and conditions of the Creative Commons Attribution license (http://creativecommons.org/licenses/by/4.0/). 